\title{
The Living Situation, and Social Capital and Its Related Factors of Adults Taking Shelter for a Long Time after the Catastrophic Earthquake
}

Mayo Hiroshima

Tokyo Healthcare University Email address: m-hiroshima@thcu.ac.jp

Manami Amagai

Mayumi Nitta

Noriko Kobayashi

National College of Nursing, Tokyo, Japan Email address: amagaim@adm.ncn.ac.jp

\author{
Makiko Takahashi \\ Miyoshi Town Office
}

Ikuko Takada

Yumiko Takeuchi

Yumiko Sawada

Okuma Town Office

Doi:10.5901/ajis.2014.v3n6p301

Abstract

This study focused on the adults taking extended shelter after the catastrophic earthquake in March 2011, and aims to reveal their living situations, and social capital and its related factors. We examined the living situations including the existence of people with whom to cohabitate, occupation, participation in community activities, and social support. We also examined the following relevant factors of social capital: area of residence, age, the existence of people with whom to cohabitate, occupation, participation in community activities, social support, mental health status, and income change after the earthquake. Help in rebuilding their community is a key factor that affects the mental sanity of refugees. Given the changes brought by the earthquake, this group of people merits government support.

Keywords: social capital, refugee, catastrophic earthquake

\section{Introduction}

After the Great East Japan Earthquake, many people had to leave their homes to spend a long time in refuges. Those who took shelter now face the task of rebuilding their own life and their communities. The social capital concept refers to "networks, norms, and trust, which are the characteristics of social activities" (Motohashi, Kaneko, \& Yamaji, 2005). Motohashi (2007) has reported that social capital is relevant to suicide prevention. Therefore, social capital is a critical concept for health and suicide prevention in communities.

We conducted this study on adults who took shelter for a long time after the earthquake. We examined their current living situations, and social capital and factors predicted to be relevant to social capital so as to identify the actual relevant factors after the earthquake. 


\section{Research Methodology}

\subsection{Participants and Procedures}

The participants were 1,595 people who applied for the general health check carried out by Town A at a venue in the prefecture. We asked participants to complete the survey form only if they agreed to cooperate in the study. The collection rate was $92.7 \%$.

\subsection{Variables/measurements}

The question items on their attributes were the following: area of residence, presence of housemate, gender, age, marital status, and employment status. The items regarding refugees' living situations were the following: the existence of people with whom to cohabitate, occupation, participation in community activities, and social support. We also examined the following factors predicted to be relevant to social capital: change in economic situation.

To determine the mental sanity, we used the Japanese version of k6 (Kawakami, 2005; Furukawa, 2003), which was developed to screen mood and anxiety disorders. The respondents could choose their answers from a five-point Likert scale: 0-Not at all, 1-Seldom, 2-Sometimes, 3-Usually, and 4-Always. The total scores from the six items (0 to 24 point range each) was calculated. A higher score indicates a lower level of mental sanity.

We also inquired on the experience of stress in the last month, availability of ways to relieve stress, as well as feeling the desire to die in the last month and/or in the past, all of which provided indices of mental sanity.

We used the scales developed by Motohashi et al. (2005) as measurement items for social capital. The questions were the following five items: (1) Are neighbors willing to help one another? (mutual assistance and trust), (2) Do people in town warn children when they happen to see the latter engaging in unsafe playtime by themselves? (sense of social responsibility), (3) Do you have an attachment to your community? (community attachment and identity), (4) Do you often speak to your neighbors? (interpersonal bond) (5) Are people in town kind to the elderly? (kindness of the community). The answers were given in a four-point Likert scale: 0-Not at all, 1-Seldom, 2-Sometimes, and 3-Often. In this study, the total scores were calculated by adding the scores of the five items ( 0 to 15 point range each). The scores were interpreted as follows: a higher total score indicated a stronger social capital level.

\subsection{Data Analyses}

We calculated the numbers and percentages of each answer regarding living situation before and after the disester.

We studied whether there was a difference in social capital depending on basic attributes, participation in community activities, the existence of social support, the existence of stress, availability of ways to relieve stress, the existence of suicide consideration, mental sanity, and change in economic situation.

We used a $t$-test to compare the two groups, and a one-way analysis of variance or Kruskal-Wallis test for more than three groups, according to the distribution. We calculated Pearson's product-moment correlation coefficient for age and mental sanity level.

We used IBM SPSS Statistics 19 for statistical analysis. The two-tailed test was conducted at a significance level of 0.05 .

\section{Findings}

\subsection{Living situation}

The results of refugees' living situations are shown in Tables 1-4 below.

Table 1: Presence of housemate

\begin{tabular}{|c|c|c|c|c|}
\hline & \multicolumn{2}{|c|}{ Before the disaster } & \multicolumn{2}{c|}{ After the disaster } \\
\hline & Number of people & $\%$ & Number of people & $\%$ \\
\hline Yes & 90 & 6.26 & 183 & 13.03 \\
\hline No & 1347 & 93.74 & 1221 & 86.97 \\
\hline Total & 1437 & 100 & 1404 & 100 \\
\hline
\end{tabular}


Table 2: Occupation

\begin{tabular}{|l|c|c|c|c|}
\hline & \multicolumn{2}{|c|}{ Before the disaster } & \multicolumn{2}{c|}{ After the disaster } \\
\hline & Number of people & $\%$ & Number of people & $\%$ \\
\hline Full-time & 354 & 24.79 & 76 & 5.39 \\
\hline Part-time & 271 & 18.98 & 68 & 4.83 \\
\hline Full-time homemaker & 164 & 11.48 & 258 & 18.31 \\
\hline Cessation from work/ Layoff & 5 & 0.35 & 98 & 6.96 \\
\hline Unemployed & 287 & 20.10 & 829 & 58.84 \\
\hline Agriculture/Forestry/Fishery & 176 & 12.32 & 8 & 0.57 \\
\hline Self-employed & 144 & 10.08 & 45 & 3.19 \\
\hline Others & 27 & 1.89 & 27 & 1.92 \\
\hline Total & 1428 & 100 & 1409 & 100 \\
\hline
\end{tabular}

Table 3: Participation in community activities

\begin{tabular}{|l|c|c|c|c|}
\hline & \multicolumn{2}{|c|}{ Before the disaster } & \multicolumn{2}{c|}{ After the disaster } \\
\hline & Number of people & $\%$ & Number of people & $\%$ \\
\hline Community-based activity & 319 & 31.96 & 122 & 22.63 \\
\hline Sports, hobby, entertainment activity & 474 & 47.49 & 269 & 49.91 \\
\hline Volunteer, NPO, civic activity & 109 & 10.92 & 86 & 15.96 \\
\hline Other groups' activity & 96 & 9.62 & 62 & 11.50 \\
\hline Total & 998 & 100 & 539 & 100 \\
\hline
\end{tabular}

Table 4: Social support

\begin{tabular}{|c|c|c|c|c|}
\hline & \multicolumn{2}{|c|}{ Before the disaster } & \multicolumn{2}{c|}{ After the disaster } \\
\hline & Number of people & $\%$ & Number of people & $\%$ \\
\hline \multicolumn{5}{|c|}{ The existence of people who listen to their frustrations } \\
\hline Yes & 1165 & 93.57 & 1077 & 86.51 \\
\hline No & 80 & 6.43 & 168 & 13.49 \\
\hline Total & 1245 & 100 & 1245 & 100 \\
\hline \multicolumn{5}{|c|}{ The existence of people who support them materially and/or financially } \\
\hline Yes & 1021 & 80.84 & 949 & 75.14 \\
\hline No & 242 & 19.16 & 314 & 24.86 \\
\hline Total & 1263 & 100 & 1263 & 100 \\
\hline
\end{tabular}

\subsection{The social capital and related factors}

The mean of the social capital score is 13.64 (SD 3.70).

The factors relevant to social capital after the earthquake were resident area, age, occupation, participation in community activities, the existence of people who listen to their frustrations, the existence of people who support them materially and/or financially, stress experienced in the last one month, availability of ways to relieve stress, the existence of suicide consideration in the past and in the last one year, mental sanity, and economical change after the earthquake.

Those categorized in the following groups had significantly lower scores for social capital than the other groups: People who have evacuated to areas other than the designated shelters, those in the age range of 40 to 59 , those with full-time employment, those who have not participated in community activities, those who stopped participating in community activities especially after the earthquake, and those who have no one to listen to their frustrations. They have no one to support them financially, are in a poor economic situation, had moderate or higher levels of stress in the last month, have no available ways to relieve stress, and have experienced the desire to die even if only slightly in the last year and in the past (Table 5). 
Table 5: Comparison of scores for social capital with scores for attributes, participation in community activities, presence of social support, changes in economic situation, and mental sanity level (shown below are items with significant difference only).

\begin{tabular}{|c|c|c|c|c|c|}
\hline & & $\begin{array}{c}\text { Number of } \\
\text { people }\end{array}$ & $\begin{array}{l}\text { Average } \\
\text { score }\end{array}$ & SD & $\begin{array}{c}\text { Test } \\
\text { statistic }\end{array}$ \\
\hline \multirow[t]{4}{*}{ Area of residence } & $A$ & 534 & $7.25^{1,2}$ & 3.650 & \multirow{4}{*}{$F=13.60$ ** } \\
\hline & $\mathrm{B}$ & 448 & $6.32^{1}$ & 3.354 & \\
\hline & Other than $A / B$ & 228 & 5.972 & 3.721 & \\
\hline & Total & 1210 & 6.66 & 3.594 & \\
\hline \multirow[t]{9}{*}{ Age } & $20 \mathrm{~s}$ & 44 & 6.20 & 3.085 & \multirow{8}{*}{$x^{2}=25.15^{\star \star x}$} \\
\hline & $30 \mathrm{~s}$ & 120 & 6.74 & 3.670 & \\
\hline & $40 \mathrm{~s}$ & 158 & $6.07^{1}$ & 3.297 & \\
\hline & $50 \mathrm{~s}$ & 227 & $5.95^{2}$ & 3.215 & \\
\hline & $60 \mathrm{~s}$ & 386 & 6.79 & 3.726 & \\
\hline & $70 \mathrm{~s}$ & 214 & $7.49^{1,2}$ & 3.717 & \\
\hline & $80 \mathrm{~s}$ & 57 & 7.25 & 3.925 & \\
\hline & 90 and above & 2 & 6.50 & .707 & \\
\hline & Total & 1208 & 6.66 & 3.590 & $\mathrm{R}=0.10^{\star \star}$ \\
\hline \multirow[t]{9}{*}{ Occupation } & Full-time & 67 & $4.94^{1,2,3,4}$ & 3.375 & \multirow{9}{*}{$F=3.00$ ** } \\
\hline & Part-time & 60 & 6.60 & 3.295 & \\
\hline & Full-time homemaker & 221 & $6.57^{1}$ & 3.379 & \\
\hline & $\begin{array}{l}\text { Cessation from work/ } \\
\text { Layoff }\end{array}$ & 84 & $7.15^{2}$ & 3.363 & \\
\hline & Unemployed & 680 & $6.67^{3}$ & 3.653 & \\
\hline & Agriculture/Forestry/Fishery & 6 & 8.67 & 5.354 & \\
\hline & Self-employed & 33 & $7.33^{4}$ & 3.434 & \\
\hline & Others & 22 & 7.27 & 4.142 & \\
\hline & Total & 1173 & 6.62 & 3.584 & \\
\hline \multirow[t]{2}{*}{ Participation in community activities } & Yes & 371 & 7.82 & 3.524 & \multirow{2}{*}{$t=7.61^{* \star}$} \\
\hline & No & 843 & 6.15 & 3.507 & \\
\hline \multirow{5}{*}{$\begin{array}{l}\text { Participation in community activities (Change } \\
\text { before and after the earthquake) }\end{array}$} & Yes, before and after & 330 & $7.82^{1,2}$ & 3.513 & \multirow{5}{*}{$F=24.86^{* *}$} \\
\hline & Before only & 294 & $5.50^{1,3,4}$ & 3.514 & \\
\hline & After only & 41 & $7.80^{3}$ & 3.655 & \\
\hline & Neither before nor after & 549 & $6.51^{2,4}$ & 3.456 & \\
\hline & Total & 1214 & 6.66 & 3.594 & \\
\hline \multirow{2}{*}{$\begin{array}{l}\text { The existence of people who listen to } \\
\text { respondents' frustrations }\end{array}$} & Yes & 1077 & 6.91 & 3.533 & \multirow{2}{*}{$t=6.92^{\star \star}$} \\
\hline & No & 137 & 4.70 & 3.471 & \\
\hline \multirow{5}{*}{$\begin{array}{l}\text { The existence of people who listen to } \\
\text { respondents' frustrations (Change before and } \\
\text { after the earthquake) }\end{array}$} & Yes, before and after & 1073 & $6.91^{1,2}$ & 3.536 & \multirow{5}{*}{$F=16.96 * \star$} \\
\hline & Before only & 77 & $4.29^{1}$ & 3.448 & \\
\hline & After only & 4 & 8.25 & 2.872 & \\
\hline & Neither before nor after & 60 & $5.23^{2}$ & 3.456 & \\
\hline & Total & 1214 & 6.66 & 3.594 & \\
\hline \multirow{2}{*}{$\begin{array}{l}\text { The existence of people who support } \\
\text { respondents' materially and/or financially }\end{array}$} & Yes & 949 & 6.94 & 3.509 & \multirow{2}{*}{$t=5.15^{\star \star}$} \\
\hline & No & 265 & 5.67 & 3.722 & \\
\hline \multirow{5}{*}{$\begin{array}{l}\text { The existence of people who support } \\
\text { respondents' materially and/or financially }\end{array}$} & Yes, before and after & 937 & $6.95^{1,2}$ & 3.500 & \multirow{5}{*}{$\mathrm{F}=9.78^{\star \star}$} \\
\hline & Before only & 80 & $5.15^{1}$ & 3.472 & \\
\hline & After only & 12 & 6.33 & 4.334 & \\
\hline & Neither before nor after & 185 & $5.89^{2}$ & 3.812 & \\
\hline & Total & 1214 & 6.66 & 3.594 & \\
\hline \multirow[t]{5}{*}{ Change in economic situation } & Worse & 571 & $6.09^{1,2}$ & 3.627 & \multirow{5}{*}{$\mathrm{F}=9.55^{\star \star}$} \\
\hline & Better & 65 & $7.88^{1}$ & 3.044 & \\
\hline & No change & 519 & $7.04^{2}$ & 3.509 & \\
\hline & Others & 20 & 6.70 & 2.922 & \\
\hline & Total & 1175 & 6.62 & 3.573 & \\
\hline
\end{tabular}




\begin{tabular}{|c|c|c|c|c|c|}
\hline \multirow[t]{5}{*}{ Stress in the last month } & Much & 455 & $5.91^{1,2}$ & 3.852 & \multirow{5}{*}{$x^{2}=41.41^{* *}$} \\
\hline & Moderate & 559 & $6.92^{1,3}$ & 3.295 & \\
\hline & Not much & 134 & $8.00^{2,3}$ & 3.347 & \\
\hline & None & 17 & 7.24 & 4.161 & \\
\hline & Total & 1165 & 6.66 & 3.602 & \\
\hline \multirow[t]{2}{*}{ Availability of ways to relieve stress } & Yes & 1093 & 6.85 & 3.568 & \multirow{2}{*}{$t=5.54^{\star \star}$} \\
\hline & No & 121 & 4.97 & 3.393 & \\
\hline \multirow[t]{4}{*}{ Experience of the desire to die in the last year } & Not really & 858 & $7.06^{1,2}$ & 3.509 & \multirow{4}{*}{$F=22.87^{* *}$} \\
\hline & Somewhat & 231 & $5.95^{1,3}$ & 3.475 & \\
\hline & Yes & 105 & $4.92^{2,3}$ & 3.852 & \\
\hline & Total & 1194 & 6.66 & 3.598 & \\
\hline \multirow[t]{4}{*}{ Experience of the desire to die in the past } & Not really & 766 & $6.95^{1}$ & 3.650 & \multirow{4}{*}{$F=8.43^{\star *}$} \\
\hline & Somewhat & 282 & 6.36 & 3.370 & \\
\hline & Yes & 140 & $5.71^{1}$ & 3.575 & \\
\hline & Total & 1188 & 6.66 & 3.599 & \\
\hline
\end{tabular}

Significant differences were observed between the same numbers.

$$
\text { * } P<0.05
$$$$
\text { ** } P<0.01
$$

The significant relationships were seen between the scores for social capital and mental sanity level (K6) in all sub-items and total scores (Table 6).

Table 6: Correlation coefficients between social capital and mental sanity level

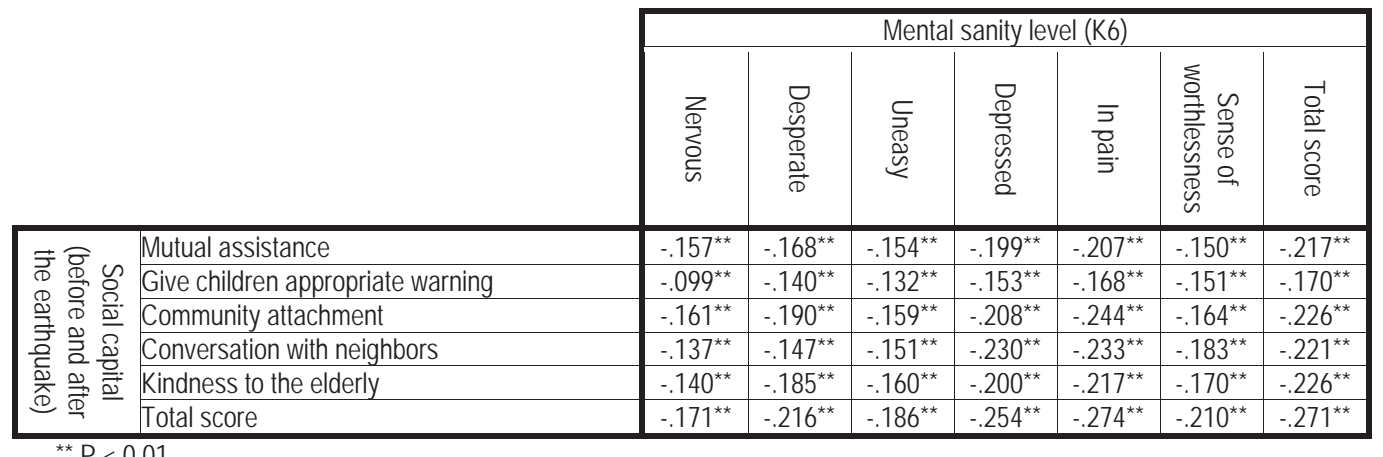

\section{Discussion}

The results showed a significant association between social capital and mental sanity levels. Associations were also seen between social capital and stress level, availability of ways to relieve stress, experience of suicide consideration, and deterioration in economic situations. Various factors are considered relevant to suicide, such as stressful daily life events in the last six months, a lack of social network, economical factors, health conditions, awareness of the people in the community, and mass media influence (Kawakami et al., 2007; Sakamoto, 2006). Recently, reports from Japan and abroad suggest that a thriving community based on trust positively affects the health of its members (Mamada, 2010; Uebuchi et al., 2008). In other words, they suggest the possibility of community members elevating the mental sanity level and preventing suicide by enriching the social capital, which is also supported by the result of this study.

According to Hiroshima et al. (in press), those who stopped participating in community activities after the earthquake had a significantly lower level of mental sanity compared with those who performed no community activities before and after the earthquake. Because those who were in a worse economic situation after the earthquake had significantly lower social capital, it is necessary to support them in view of the changes that occurred after the earthquake. 


\section{Conclusion}

In this study we examined the living situation as well as the social capital and its relevant factors for adults taking extended shelter after the catastrophic earthquake in March 2011. Social capital was strongly relevant to mental sanity levels. In addition, it was associated with economic changes after the earthquake. Providing support in rebuilding their community is a key factor that affects the mental sanity of refugees. They must be given support in view of the changes that occurred after the earthquake.

\section{References}

Furukawa, T. (2003). Study on Convenient Screening for Mental Health in the General Population. The 2002 Health and Labour Sciences Research Grants (MHLW Special Research Projects). "Study on the current state of mental health problems and its infrastructure measures." Cooperative Study Report. mental.m.u-tokyo.ac.jp/h14tokubetsu/ SharedStudyReport2-2.pdf

Hanibuchi, T., Murata, Y., Ichida, Y., Hirai, H., Kondo, K. An evaluation of an area's social capital by public health nurses. Japanese Journal of Public Health, 55(10), 716-723.

Hiroshima, M., Takahashi M., Sawada Y., \& Nitta, T. Japan Welfare/Mutual Aid Promotion Association for Workers (Zenrousai Kyoukai), Report on Consignment Study by Public Recruitment. "Study on construction of social bonding and mental health of adults who live in shelters for an extended time after the earthquake." (in press)

Kawakami, N. (2005). Study on mental health related to suicide prevention measures for adults. The 2004 MHLW Grants System Mental Health Science. "Study on promotion of preventive measures based on the current status of suicide." Shared Study Report. http://ikiru.ncnp.go.jp/ikiru-hp/report/ueda16/ueda16-8.pdf

Kawakami N. (2007). Review of the pilot study on psychological autopsy evaluation: Analysis of factors related to suicide by case-control study. The 2006 MHLW Grants System Mental Health Science. "Study on promotion of preventive measures based on the current status of suicide." General study report. http://ikiru.ncnp.go.jp/ikiru-hp/report/ueda18/ueda18-1.pdf

Mamada, T. (2010). Social capital and health studies in Japan: Present and future. Bulletin of Aichi Prefectural University School of Nursing \& Health, 16, 1-7.

Motohashi Y., Kaneko Y., \& Yamaji M. (2005). Social capital and suicide prevention. Akita Journal of Public Health, 3(1),21-31.

Motohashi Y. (2009). Study for effectiveness of community-based suicide prevention - Construction of social capital model -. The 2007 business year report of the Grant-in-Aid for Scientific Research by Ministry of Education, Science, Sports and Culture. http://kaken.nii.ac.jp/pdf/2009/seika/jsps-1/11401/18390193seika.pdf

Sakamoto, S. (2006). Psychology/social causes of suicide: What should be taken into consideration for suicide prevention. The Japanese journal of stress sciences, 21(1), 42-53. 